\title{
Effect of Microstructural Variations Developed by heat Treatment On the Mechanical and Electrical Properties of (Pb-1.5 wt \% Sb)
}

\author{
E.M.Sakr ${ }^{1}$, M.R. Nagy $^{2}$, A.S.Mahmoud ${ }^{2}$ \\ ${ }^{(1)}$ University college of Girls and ${ }^{(2)}$ faculty of Education \\ Ain Shams University, Cairo, Egypt
}

\begin{abstract}
The purpose of the present work is to investigate the effect of microstructural variations of the annealed (Pb-1.5 wt \% Sb) alloy during the phase transformation, on their mechanical and electrical properties. Creep tests on the studied alloy (slow cooled) were made under different constant stresses ranging from $12 \mathrm{MPa}$ to $15 \mathrm{MPa}$ near the transformation temperature. Transient and steady state creep of this alloy showed a transition point at $443 \mathrm{~K}$. The transient creep parameters ( $\beta$ and $n$ ) were found to change with the applied stress and ageing temperature. The value of the time exponent $(\gamma)$ was found to be 0.45 , the activation energy of both the transient and steady state creep was found to be $42 \mathrm{~kJ} / \mathrm{mole}$ and $52 \mathrm{~kJ} / \mathrm{mole}$ respectively above $443 \mathrm{~K}$. It was found that the strain rate sensitivity parameter (m) has the values ranging from 0.17 to 0.35 . The microstructure of the deformed alloy samples were investigated by : X-ray diffraction technique which showed that the residual internal lattice strain was at $443 \mathrm{~K}$. Transmission electron microscopy and electron diffraction results showed good agreement with the $X$ ray analysis. The dependence of the resistivity changes on the ageing temperatures were also studied. The activation energy of the precipitation process was found to be ranged from 0.07 to $0.09 \mathrm{ev}$, below and above $443 \mathrm{~K}$ respectively.
\end{abstract}

\section{Introduction}

Lead-based babbitts consisting of hard intermetallics dispersed in a $\mathrm{Pb}$-based solution, are important bearing materials. These materials are good for embedding hard contaminant particles and resistance to galling, but fatigue quickly. 
The binary $(\mathrm{Pb}-\mathrm{Sb})$ alloy, is utilized in industry. It has been widely used as the grid metal for lead-acid batteries for many years [1]. Unfortunately, antimony has various electrochemical, side effects $[2,3]$ in addition to its useful strengthening role. The addition of antimony is not only harden the alloy and make it more resist to compressive impact and wear, but also lower the casting temperature and minimize contraction during freezing $[4,5]$.

Thus the primary purpose of $\mathrm{Sb}$ additions is to produce strength in terms of solid solution strength in the $\mathrm{Pb}$-rich phase, and via the dispersion effect of a finely divided eutectic mixture [6].

Some mechanical and structural properties of a series of $\mathrm{Pb}-\mathrm{Sb}$ alloys containing different additives were studied [7]. The thermally induced elastic stresses were found to affect the mechanical properties of the eutectic $\mathrm{Pb}-\mathrm{Sb}$ alloy, which showed a low plasticity at room temperature [8]. The study of the effect of temperature and stress on the structure and creep parameters of a $\mathrm{Pb}$ $2 \mathrm{wt} \% \mathrm{Sb}$ alloy given by $[9,10]$ revealed a transition point at $473 \mathrm{~K}$. The samples originally contain both $\mathrm{Pb}$ - rich phase ( $\alpha$-phase) and $\mathrm{Sb}$ - rich phase ( $\beta$ - phase). Ageing was found to change the defect structure of $\mathrm{Pb}-\mathrm{Sb}$ alloys [11]. The effect of structure transformation on the stress - strain characteristics of a $\mathrm{Pb}-3 \mathrm{wt} \% \mathrm{Sb}$ alloy was investigated [12]. The variations observed in the measured parameters point to two temperature regions around the transformation temperature $(503 \mathrm{~K})$ which characterizes the magnitude of variation of these parameters. The dependence of the steady state creep rate of the $\mathrm{Pb}-11.2 \mathrm{wt} \% \mathrm{Sb}$ alloy [13] on the temperature reflects a thermally activated change in the atomic arrangement of the alloy at the transition temperature.

Annealing serves to decrease the resistivity due to removal imperfections which acts as scattering centers for electrons [14]. If the alloy is aged at temperature lower than the solid solution temperature, precipitation of the solute atoms will take place and the alloy will show resistivity variations depending on the nature of the solute atoms aggregation [15].

This study is concerned with the measurement of tensile strain associated with transient and steady state creep of $(\mathrm{Pb}-1.5 \mathrm{wt} \% \mathrm{Sb})$ annealed alloy. The relation: $\beta=\beta \mathrm{o}\left(\varepsilon_{s t}^{*}\right) \gamma$ correlated transient to steady state creep where, $\beta$ - is the transient creep parameter and, $\gamma$ - is an exponent. Both transient and steady state creep depend on the applied stress, ageing temperature and microstructure of the samples. On account of this fact, it was interesting to investigate the effect of phase transformation on the mechanical properties of the test alloy. Variation in the microstructure and phase formation, due to 
precipitation and dissolution in the aged samples, were aimed to be investigated by X-ray diffraction and electron microscope techniques.

Moreover, the variation of the electrical resistivity during different ageing temperatures were studied.

\section{Experimental Techniques:}

The studied alloy was prepared in ordinary vertical furnace from the constituent elements $(\mathrm{Pb}, 99.9 \%, \mathrm{Sb}, 99.9 \%)$ in graphite crucible by melting. It was homogenized at $443 \mathrm{~K}$ for $72 \mathrm{~h}$, then it was swaged into wires of diameter $\left(5 \times 10^{-4}\right.$ and $\left.1 \times 10^{-3}\right) \mathrm{m}$ and length $\left(5 \times 10^{-2}\right) \mathrm{m}$.

The samples were annealed for $2 \mathrm{~h}$ at $503 \mathrm{~K}$ to eliminate the cold work introduced during swaging, then slowly cooled with cooling rate $2.5 \times 10^{-3} \mathrm{~K} \mathrm{sec}^{-1}$ to room temperature. The accuracy of temperature measurements is of the order of $\pm 1 \mathrm{~K}$.

Creep deformation of test wires were studied using an apparatus of the conventional type which is in some aspects similar to that previously described by Sakr [16]. Elongation measurements were done with an accuracy of $\pm 1 \mu \mathrm{m}$.

The electrical resistivity of the test wires were measured using 2-probKelvin double bridge [17].

For structural investigation in this study, X-ray diffraction patterns by using a Philips diffractometer[18] and transmission electron microscope JEOL/JEM-100s were utilized. The accelerating voltage in case of e.m. was $(80 \mathrm{kV})$.

\section{Experimental Results and Discussion}

Fig.(1) shows creep curves of ( $\mathrm{Pb}-1.5 \mathrm{wt} \% \mathrm{Sb}$ ) annealed alloy using different applied stresses from $12 \mathrm{M} \mathrm{Pa}$ to $15 \mathrm{M} \mathrm{Pa}$ at various ageing temperatures from ( $413 \mathrm{~K}$ to $473 \mathrm{~K})$ in steps of $10 \mathrm{~K}$. It is clear from Fig.(1) that the slopes of the linear parts of curves are dependent on the applied stress and the ageing temperature. Also, it is clear from this figure that as the stress increases the strain rate of each curve is increased at the same ageing temperature. From the creep curves we noticed that increasing the ageing temperature led to an increase in the steady state creep rate $\left(\varepsilon_{s t}^{*}\right)$ until and after phase transformation has occured. This phase deformation is due to both the increasing in temperatures and the applied stresses. 


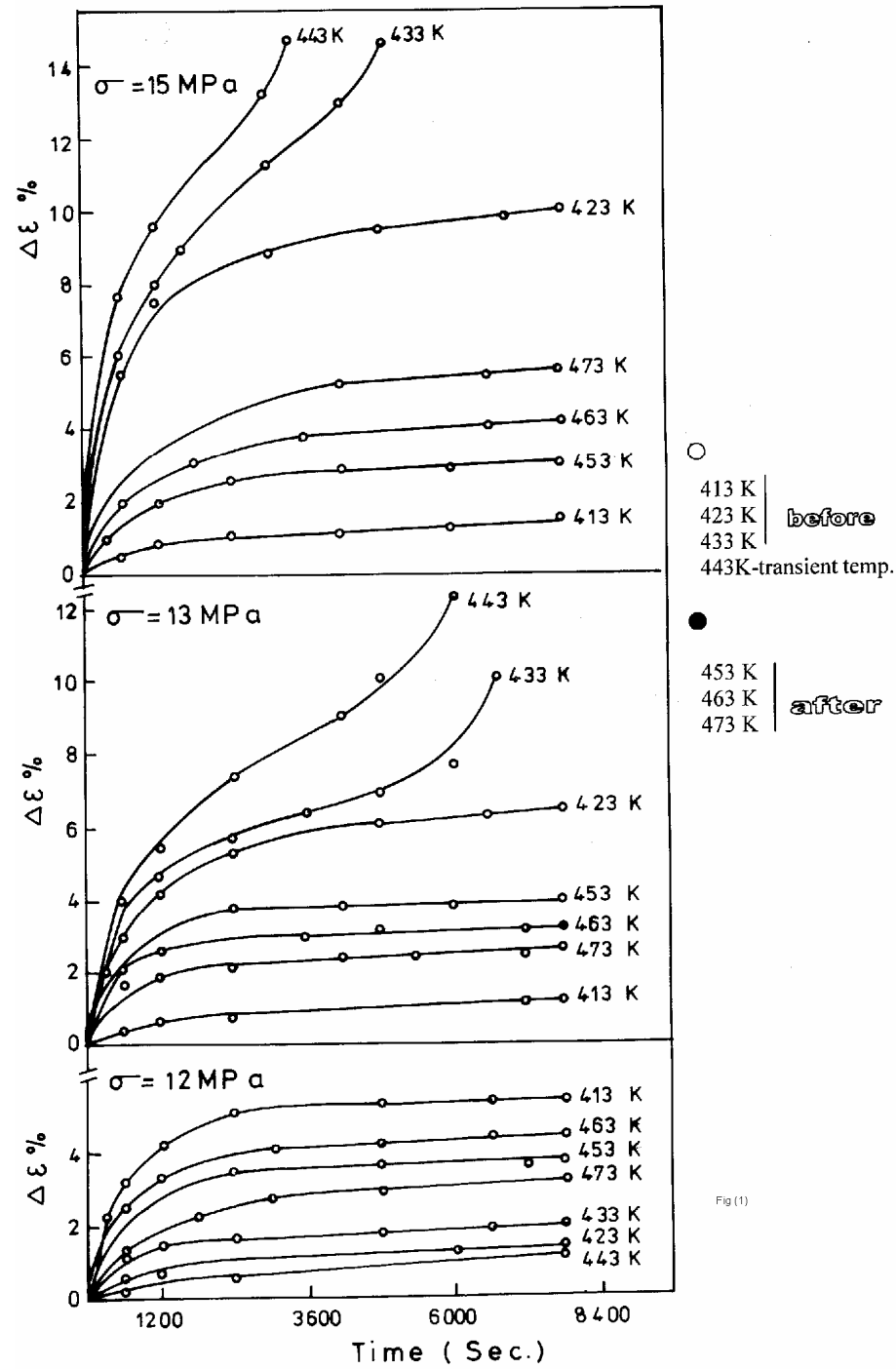

Fig. (1): The creep curves of annealed $(\mathrm{Pb}-1.5 \mathrm{wt} \% \mathrm{Sb})$ alloy different constant applied stresses at different ageing temperatures.

By performing creep tests for the studied alloy, it was expected in accordance with the phase diagram [19], that in the temperature region below $433 \mathrm{~K}$, there is $\alpha$-phase ( $\mathrm{Pb}$-rich phase), dark phase and $\beta$-phase $(\mathrm{Sb}$ - rich phase), light phase. Then the solubility of $(\mathrm{Sb})$ in $(\mathrm{Pb})$ increases with increasing the ageing temperature until the transition temperature $443 \mathrm{~K}$, after which the $\beta$ - 
phase is dissolved complitily in $\alpha$-phase [19]. This increasing in solubility could well be related to the observed changes of both transient and steady state creep strain rates at high temperature.

Figure (2) shows the relation between $\ln \varepsilon_{t r}$ and $\ln t$ for the studied alloy under different applied stresses from $12 \mathrm{MPa}$ to $15 \mathrm{MPa}$ at different ageing temperature ranging from $413 \mathrm{~K}$ to $473 \mathrm{~K}$. Straight lines due to temperature steps were observed.

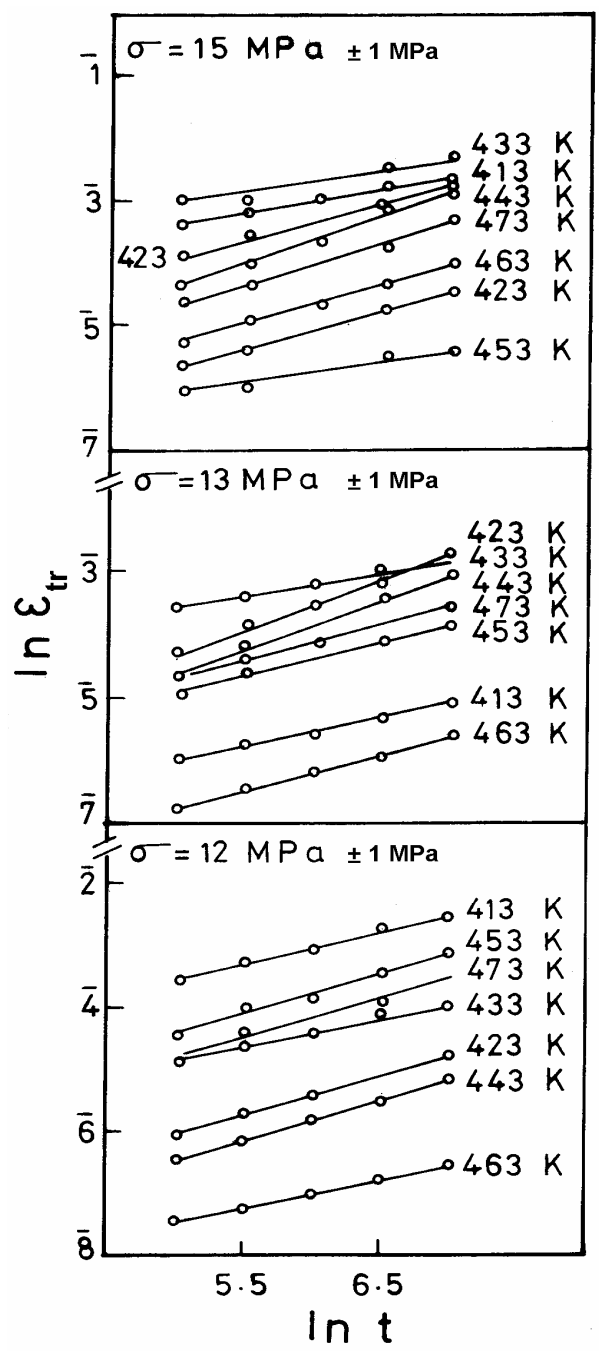

Fig. (2): Relation between $\ln \varepsilon_{t r}$ and $\ln \mathrm{t}$ for annealed ( $\left.\mathrm{Pb}-1.5 \mathrm{wt} \% \mathrm{Sb}\right)$ alloy at different ageing temperatures and under different applied stresses. 
Figure (3) shows the relation between transient creep parameters ( $\beta$ and n) with ageing temperature. There is a gradual decrease in each of transient creep parameters until $443 \mathrm{~K}$. This behavior might be attributed to the alloying elements, which are retained in solid solution. Several interactions are possible, one of them is the elastic (cottrell) interaction which occurs between stress field caused by a dislocation and the stress field caused by the misfit of solute atoms in the lattice. The lattice structure is destroyed by a moving dislocation, and chemical interaction arising from the segregation of solute atom to stacking faults of extended dislocation. The rapid increase of these parameters above $443 \mathrm{~K}$ might be attributed to complete dissolution of the $\beta$-phase (Sb-rich phase) in the matrix which facilitates the moving of pinning dislocation [20].

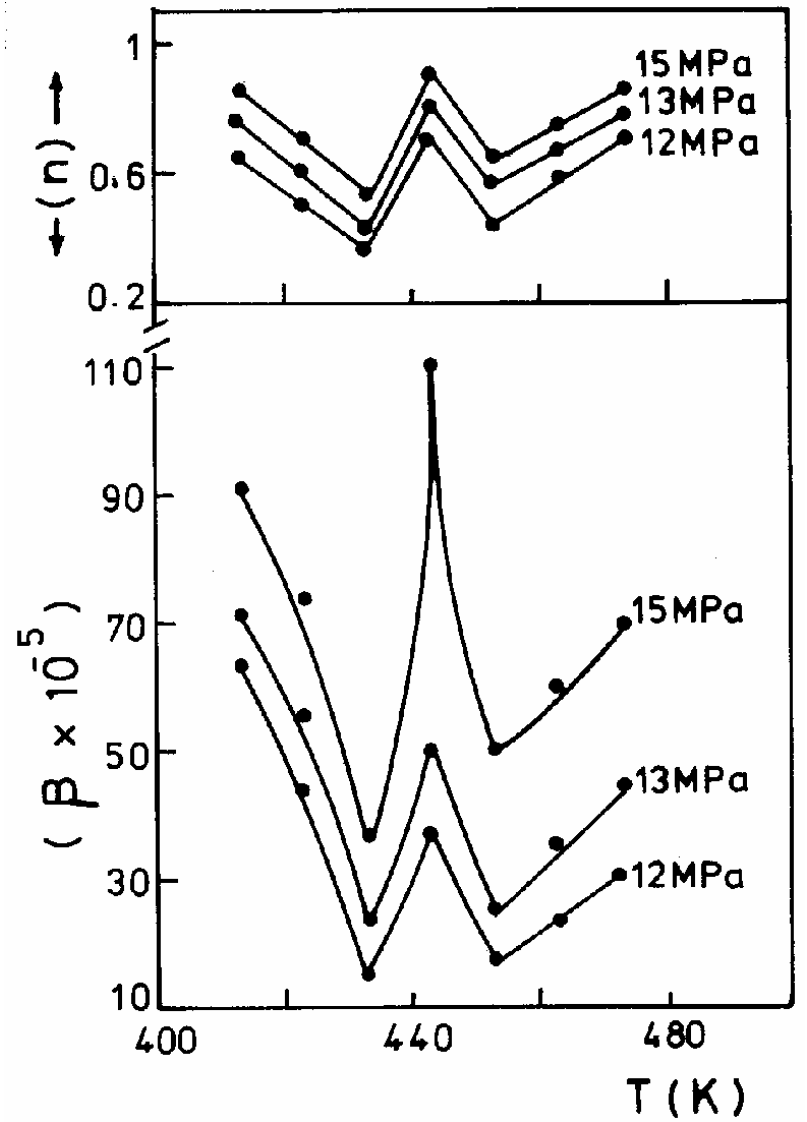

Fig. (3): The dependence of transient creep parameters $\beta$ and $n$ on the different ageing temperatures at different applied stresses for annealed $(\mathrm{Pb}-1.5$ $\mathrm{wt} \% \mathrm{Sb}$ ) alloy. 
Figure (4) shows the linear relation between $\ln \beta$ and $\ln \varepsilon_{s t}^{*}$, which correlate transient to steady state creep. From this relation $\gamma$ was found to be 0.45. The dependence of $(\beta)$ on the strain rate of the steady state creep $\left(\varepsilon_{s t}^{*}\right)$ seems to be induced by the transformation which enhance the transient and the steady state stages [21].
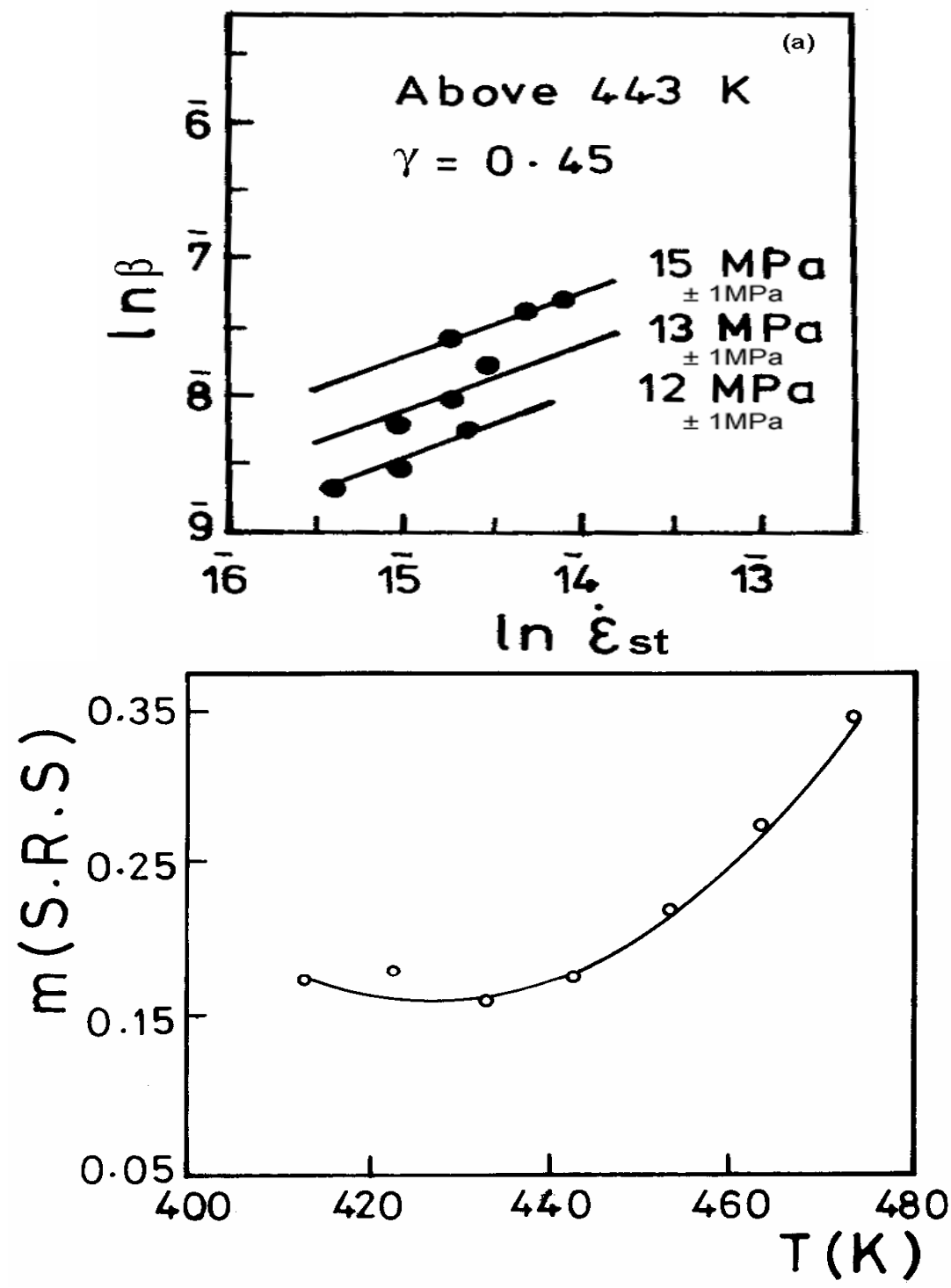

Fig. (4): The relation between $\ln \beta, \ln \varepsilon_{s t}^{*}$ for annealed (Pb-1.5 $\mathrm{wt} \% \mathrm{Sb}$ ) alloy 
The activation energy of creep [22] was calculated from the straight lines relating $\ln \beta$ and $10^{3} / \mathrm{TK}^{-1}$ as shown in Fig (5). In the temperature range above $443 \mathrm{~K}$, the activation energy was found to be $42 \mathrm{KJ} / \mathrm{mole}$, which characterize the mechanism of grain boundary sliding [23]. Below 443K, the activation energy was found to be $52 \mathrm{KJ} / \mathrm{mole}$ which characterizes a dislocation intersection mechanism. This might be due to accumulation of the dislocation obstacles produced by the salute atom $(\mathrm{Sb})$.
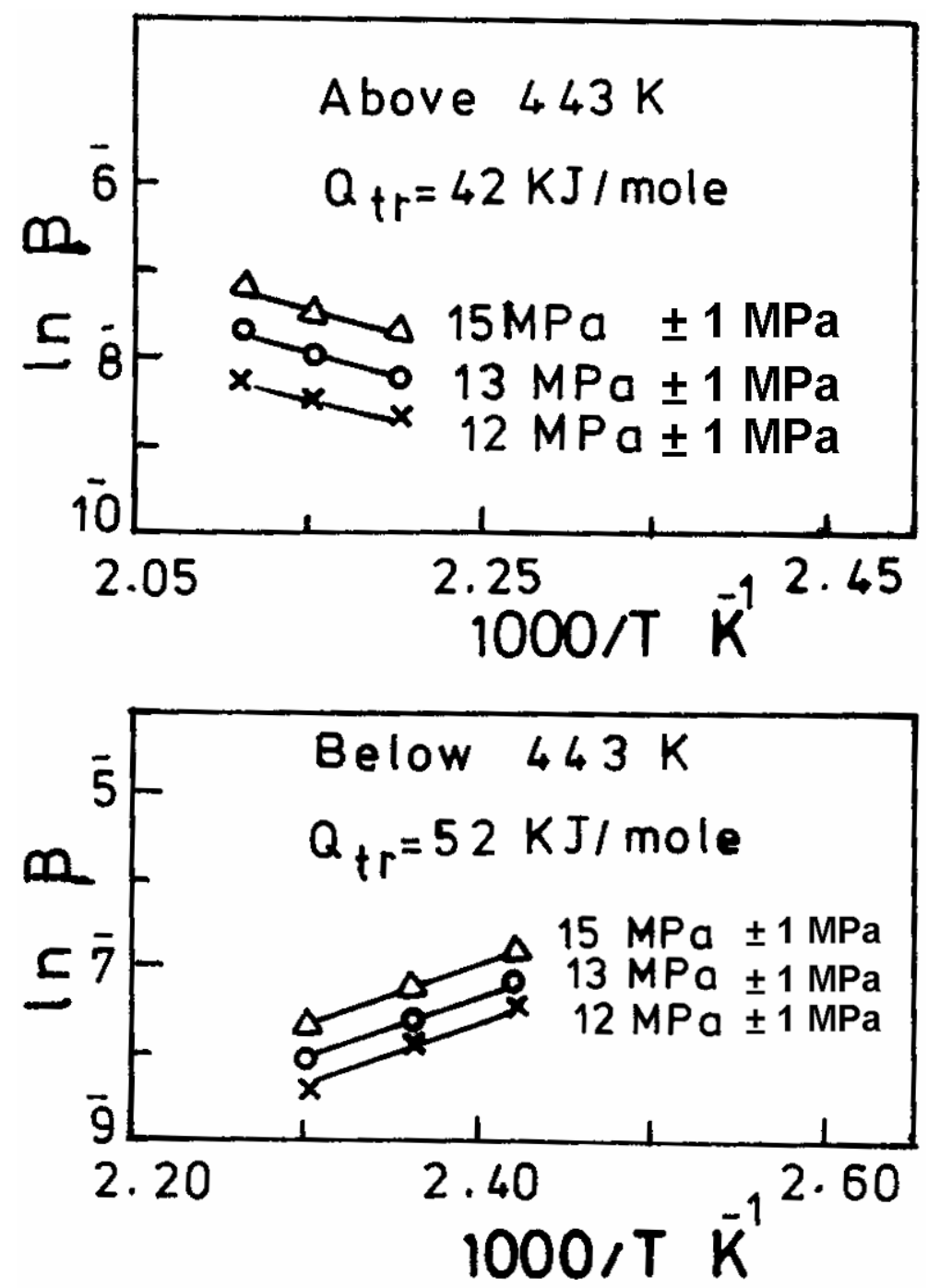

Fig. (5): The relation between $\ln \beta$ and $10^{3} / \mathrm{TK}^{-1}$ for annealed ( $\mathrm{Pb}-1.5 \mathrm{wt} \% \mathrm{Sb}$ ) alloy at different applied stresses. 
Figure (6) shows the relation between the steady state creep rates $\left(\varepsilon_{s t}^{*}\right)$ at the different applied stresses versus the different ageing temperatures for the tested alloy, in which $\left(\varepsilon_{s t}^{*}\right)$ was calculated from the slope of the linear parts of the creep curves given in Fig. (1). The relations show gradual increases of $\varepsilon_{s t}^{*}$ until $443 \mathrm{~K}$, which might be attributed to segregation of $\beta$-phase, Sb-rich phase (light phase) around the columnar shape for $\alpha$-phase, $\mathrm{Pb}$-rich phase (dark phase). This is followed by rapid decrease for $\varepsilon_{s t}^{*}$ above $443 \mathrm{~K}$, and then show an increase. This may be due to the dissolution of Sb-rich particles and then the alloy becomes homogenized.

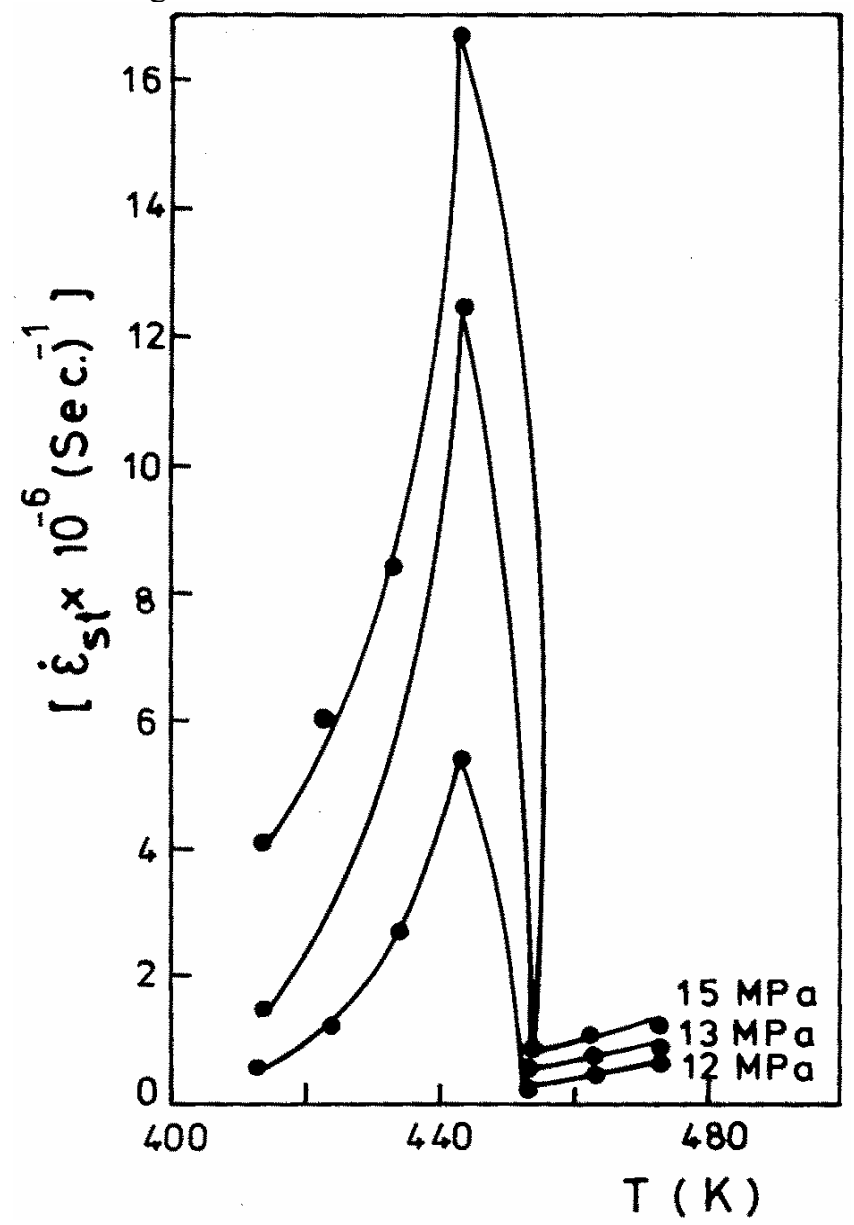

Fig. (6): The relation between $\varepsilon_{s t}^{*}$ and different ageing temperatures at different applied stresses for annealed ( $\mathrm{Pb}-1.5 \mathrm{wt} \% \mathrm{Sb})$ alloy. 
Figure (7) shows the stress dependence $(\ln \sigma)$ on $\ln \left(\varepsilon_{s t}^{*}\right)$ for the studied alloy and from which the strain rate sensitivity parameter $\left(\mathrm{m}=\partial \ln \sigma / \partial \ln \varepsilon_{s t}^{*}\right)$ was calculated. It was found that $(\mathrm{m})$ increases from $(0.17$ to 0.35$)$ with increasing ageing temperature as shown in Fig. (8). This was attributed to the change from cross-slipping to climb dislocation mechanisms [24] with the temperatures.

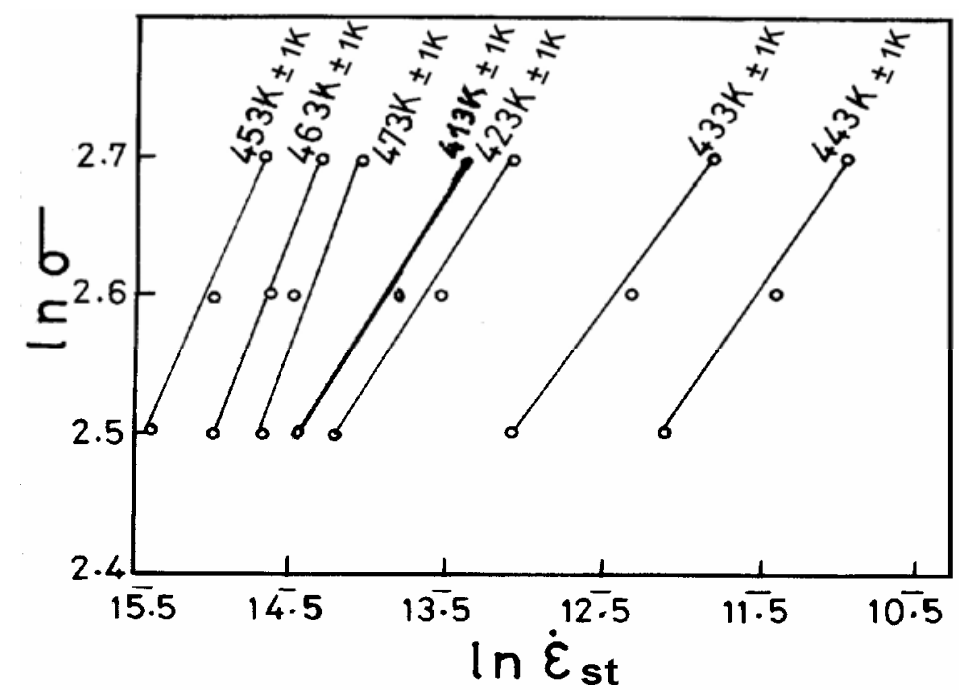

Fig. (7): The relation between $\ln \sigma$ and $\ln \varepsilon_{s t}^{*}$ at different ageing temperatures for annealed $(\mathrm{Pb}-1.5 \mathrm{wt} \% \mathrm{Sb})$ alloy.

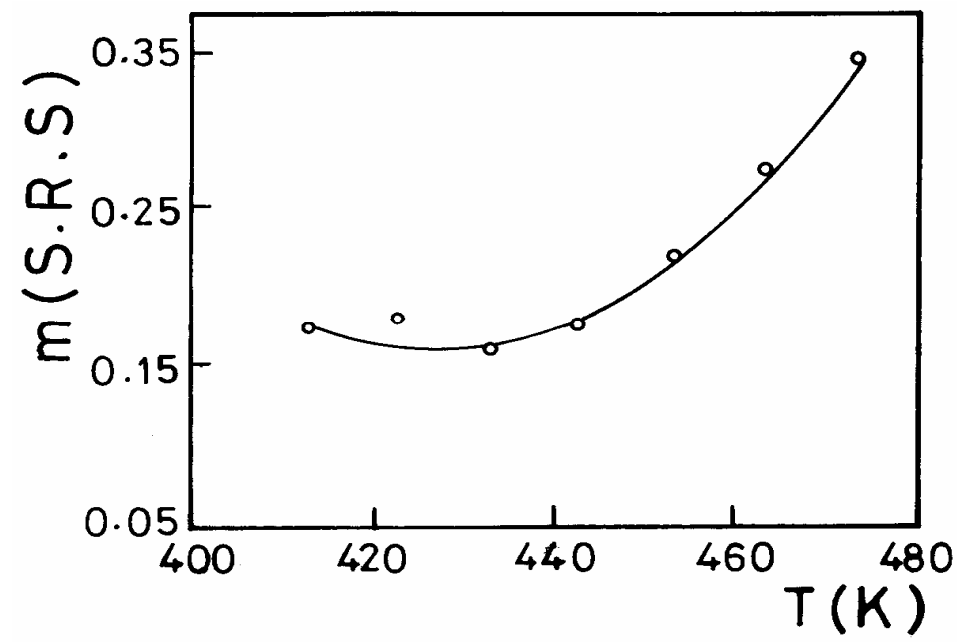

Fig. (8): The relation between the strain rate sensitivity parameter $(\mathrm{m})$ and the different ageing temperatures for annealed $(\mathrm{Pb}-1.5 \mathrm{wt} \% \mathrm{Sb})$ alloy. 
In accordance with the obtained results of $\varepsilon_{s t}^{*}$, we found that any increase in $\varepsilon_{s t}^{*}$ is belonging to the increasing in the ageing temperature and dissolution precipitates Sb- rich phase ( $\beta$ - phase). Hence, it is expecting that the transition point to be at $443 \mathrm{~K}$, and that is in agreement with the results obtained for the transient creep as shown in Fig. (3).

The activation energies of the apparent steady state creep $\left(\mathrm{Q}_{\mathrm{st}}\right)$ for the studied alloy were found to have values $(150 \mathrm{~kJ} / \mathrm{mole}$ and $52 \mathrm{~kJ} / \mathrm{mole})$ below and above $443 \mathrm{k}$ respectively Fig. (9). These values refer to self diffusion in lead [25] and grain boundary diffusion [22], respectively.
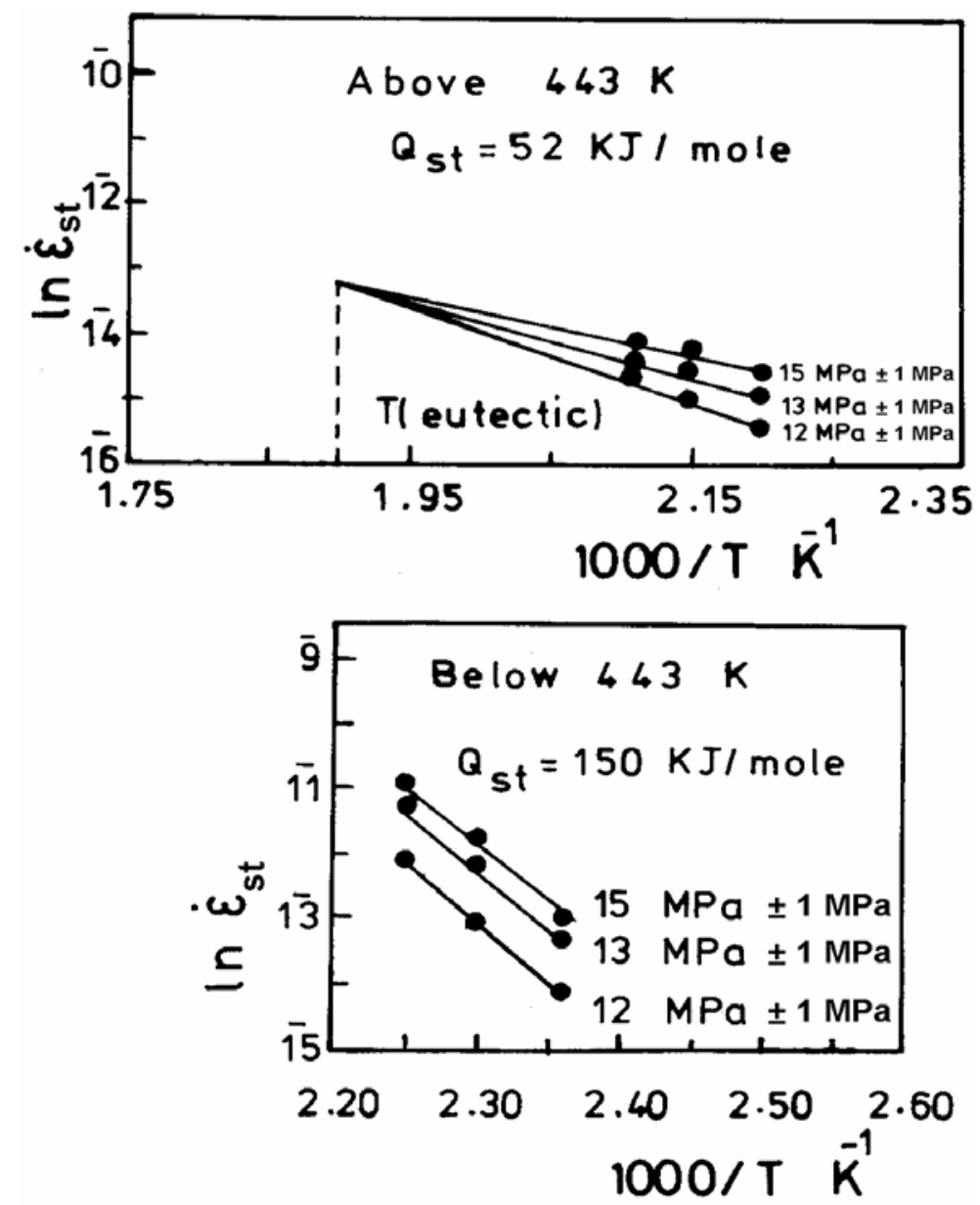

Fig. (9): The relation between $\ln \varepsilon_{s t}^{*}$ and $10^{3} / \mathrm{T} \mathrm{K}^{-1}$ at different applied stresses for annealed $(\mathrm{Pb}-1.5 \mathrm{wt} \% \mathrm{Sb})$ alloy. 
These results showed that in the low and high temperature range, the steady state creep is governed by a thermally activated, stress assisted process for which $525 \mathrm{~K}$ is critical temperature as shown in the Fig. (9) coincident with the eutectic temperature of the $(\mathrm{Pb}-\mathrm{Sb})$ system [19].

Figure (10), shows the X-ray diffraction pattern in the range of diffraction angle $2 \theta\left(20^{\circ}-92^{\circ}\right)$ for the deformed samples under the applied stress $15 \mathrm{MPa}$ and different ageing temperatures. This figure illustrates the existence of many peaks, these peaks and corresponding d-spacings (interplanar distance) match with existing standard phases referenced in the available literature [26]. The first three peaks intensities of Pb- lines (111), (200), and (220) are attributed to the variations of the re-orientation of grains [20].

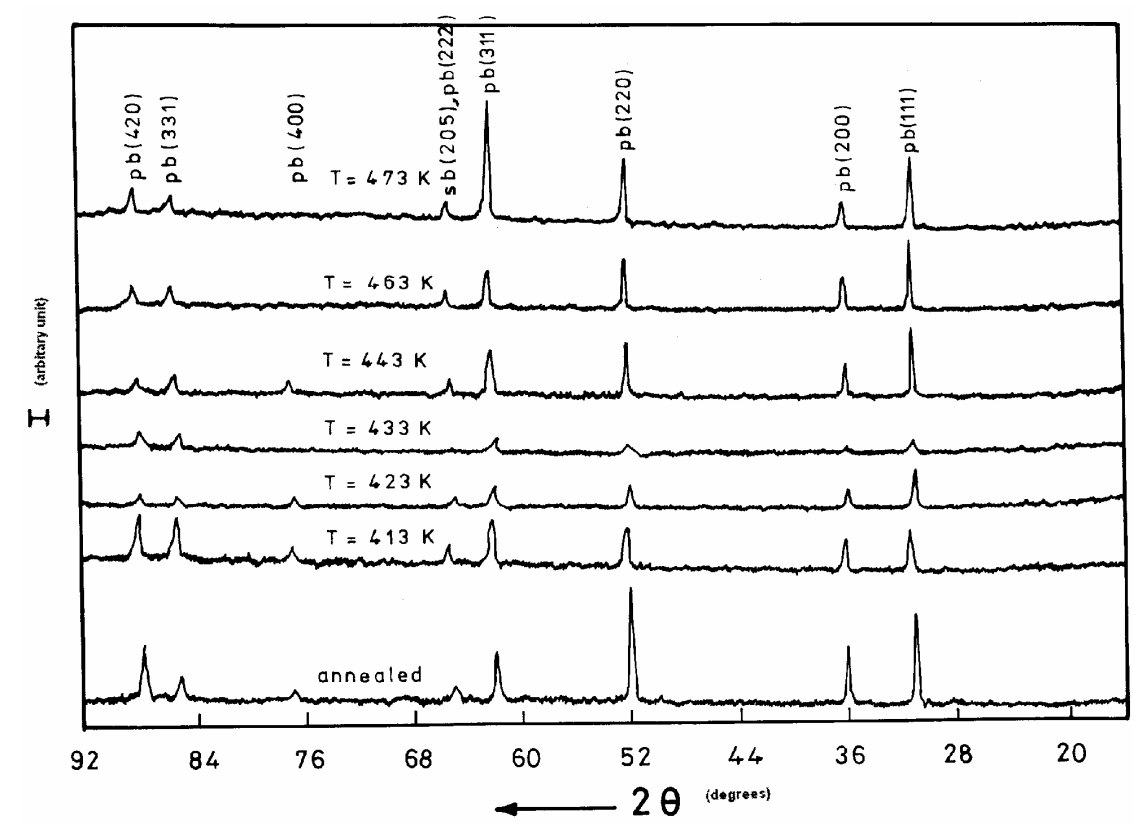

Fig. (10): X-ray diffraction pattern for annealed (Pb-1.5 wt \% Sb) alloy after creep deformation under applied stress $15 \mathrm{MPa}$ at different ageing temperatures.

Figure (11), shows the dependence of the integral intensity (I) and the half line width $(\Delta 2 \theta)$ with the working on temperatures. It was found that I and $\Delta 2 \theta$, decreases with increasing the ageing temperature below $443 \mathrm{k}$, above which (I and $\Delta 2 \theta$ ) increases with increasing ageing temperature. This is attributed to the increase of the dissolution rate of the solute atoms $(\mathrm{Sb})$ in $\alpha$ phase ( $\mathrm{Pb}$-rich phase) by a thermally activated and stress assisted force. The decreasing in their values to minima indicates that the residual internal lattice 
strain decreased appreciably in the $\alpha$-phase owing to the relaxation process of the cross-slipping dislocation [27]. The change in $\Delta 2 \theta$ could also be related to the amount of strain in the matrix,which is also affected by the amount of dissolution.

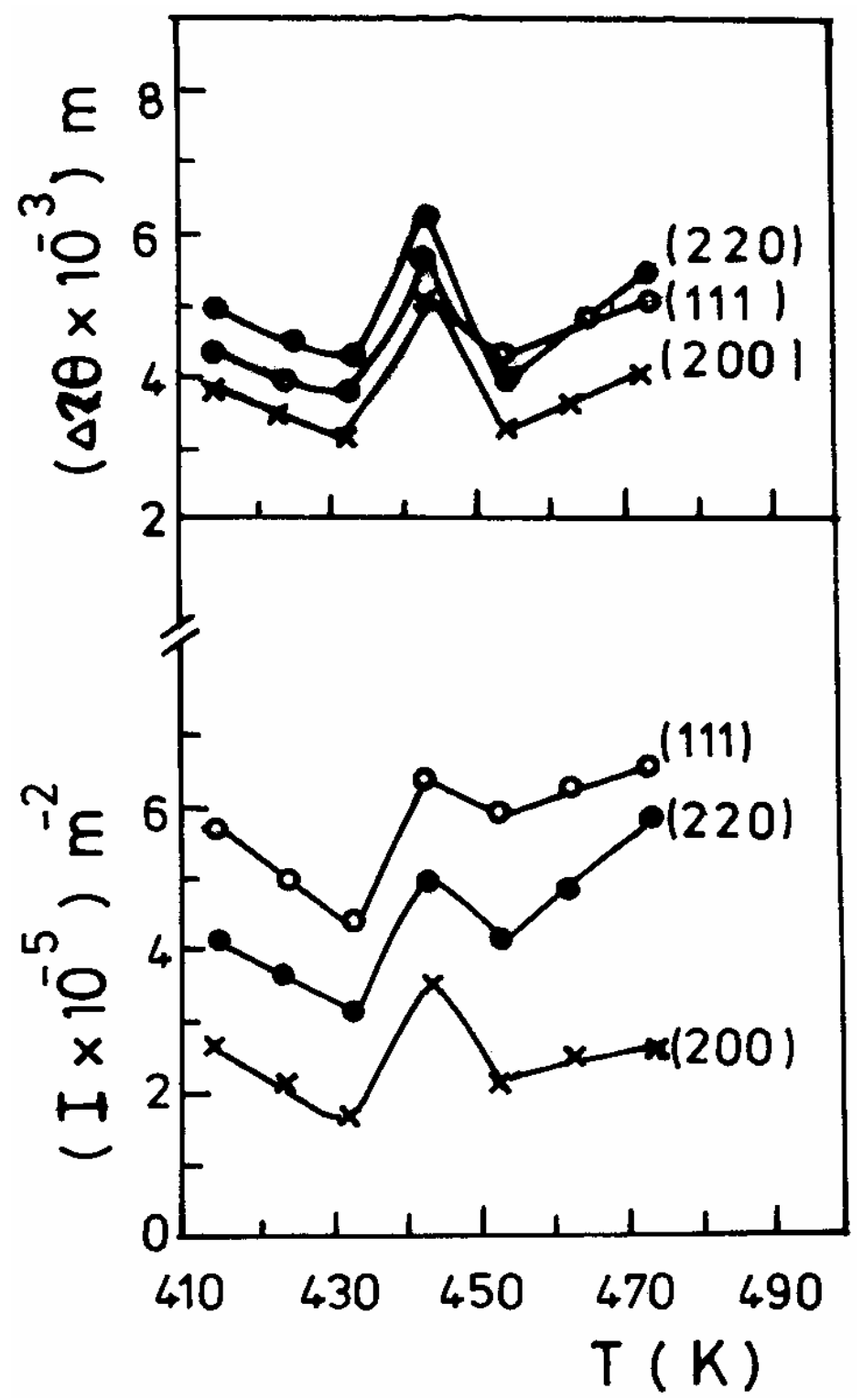

Fig. (11): The effect at different ageing temperatures on the integral X-ray intensity (I) and the half line width $(\Delta 2 \vartheta)$ for annealed $(\mathrm{Pb}-1.5 \mathrm{wt} \% \mathrm{Sb})$ alloy. 
The changes in $\left(\rho_{t} / \rho_{0}\right)$ for the studied alloy is shown in Fig. (12) in the temperature range (393-433)K. The $\left(\rho_{t} / \rho_{0}\right)$ increases with increasing the ageing time depending on the ageing temperature, except at $423 \mathrm{~K}$ which is in the vicinity of the transformation temperature $443 \mathrm{~K}$. A slight decrease of the $\left(\rho_{t} / \rho_{0}\right)$ against time (t) was observed followed by constant values independent of time. In the temperature range (443-473)k, $\left(\rho_{t} / \rho_{0}\right)$ decreases with increasing ageing time depending on the ageing temperature followed by constant values independent of time. The maximum value of $\left(\rho_{t} / \rho_{0}\right)$ was found to depend on the ageing temperature and ageing time.

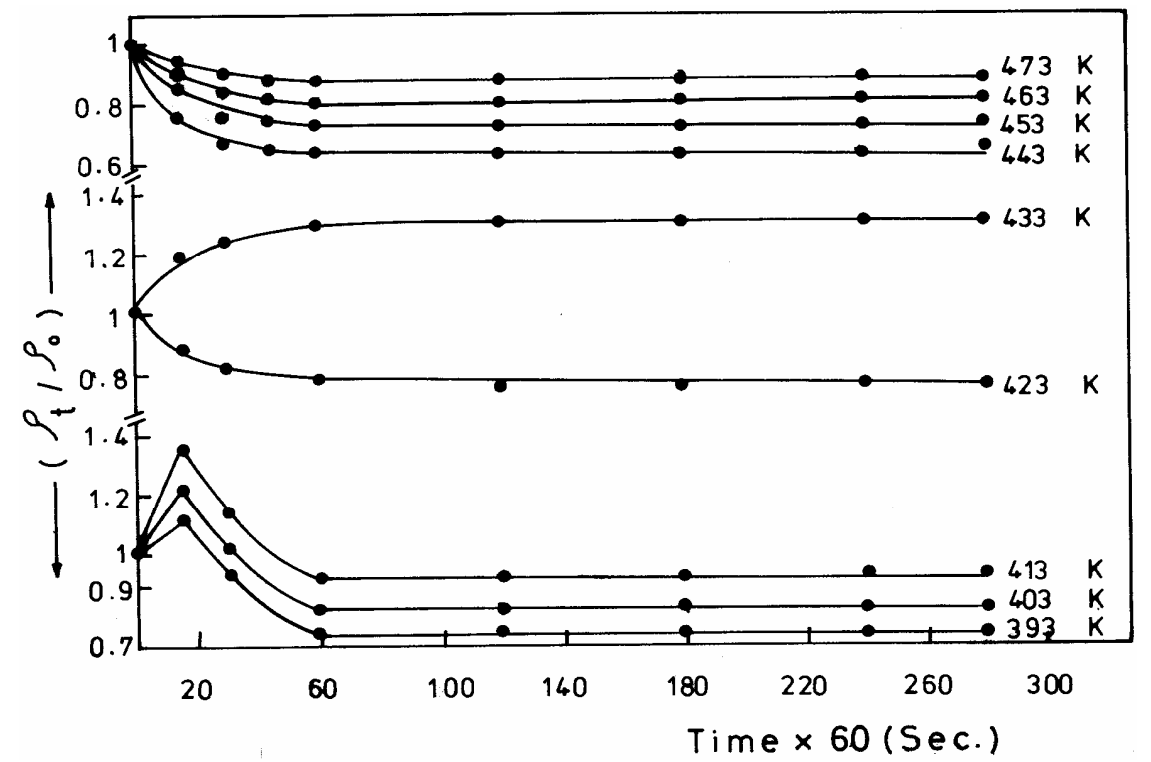

Fig. (12): Time dependence of isothermal resistivity ratio $\left(\rho_{t} / \rho_{0}\right)$ for the annealed (Pb- $1.5 \mathrm{wt} \% \mathrm{Sb}$ ) alloy.

The explanation of this behavior might be due to the formation of the precipitated particles (Sb-rich phase) where they act as scattering centers for the conduction electrons. Then the ratio $\left(\rho_{t} / \rho_{0}\right)$ is decreasing with increasing the ageing time. This might be attributed to the slight variation in the number of scattering centers for the conduction electron [28].

In the second stage above $443 \mathrm{~K}$ the decreasing of the $\left(\rho_{t} / \rho_{0}\right)$ with increasing the ageing time is attributed to the completely soluble of $\beta$-phase (Sb-rich phase) in $\alpha$-phase pb-rich[19]. Then the scattering centers for 
conduction electrons decreased so that $\left(\rho_{t} / \rho_{0}\right)$ will decrease and consequently the conductivity increase.

The activation energy of the two stages which represents the formation and dissolution processes of (Sb-phase) in each ageing stage was calculated from the linear change of the relation between $\ln \left(\rho_{t} / \rho_{0}\right)$ versus $10^{3} / \mathrm{TK}^{-1}$ for different ageing times as shown in Fig. (13). The values of the activation energy were found to range from $(0.07$ to 0.09$) \mathrm{eV}$, below and above $443 \mathrm{k}$ respectively.
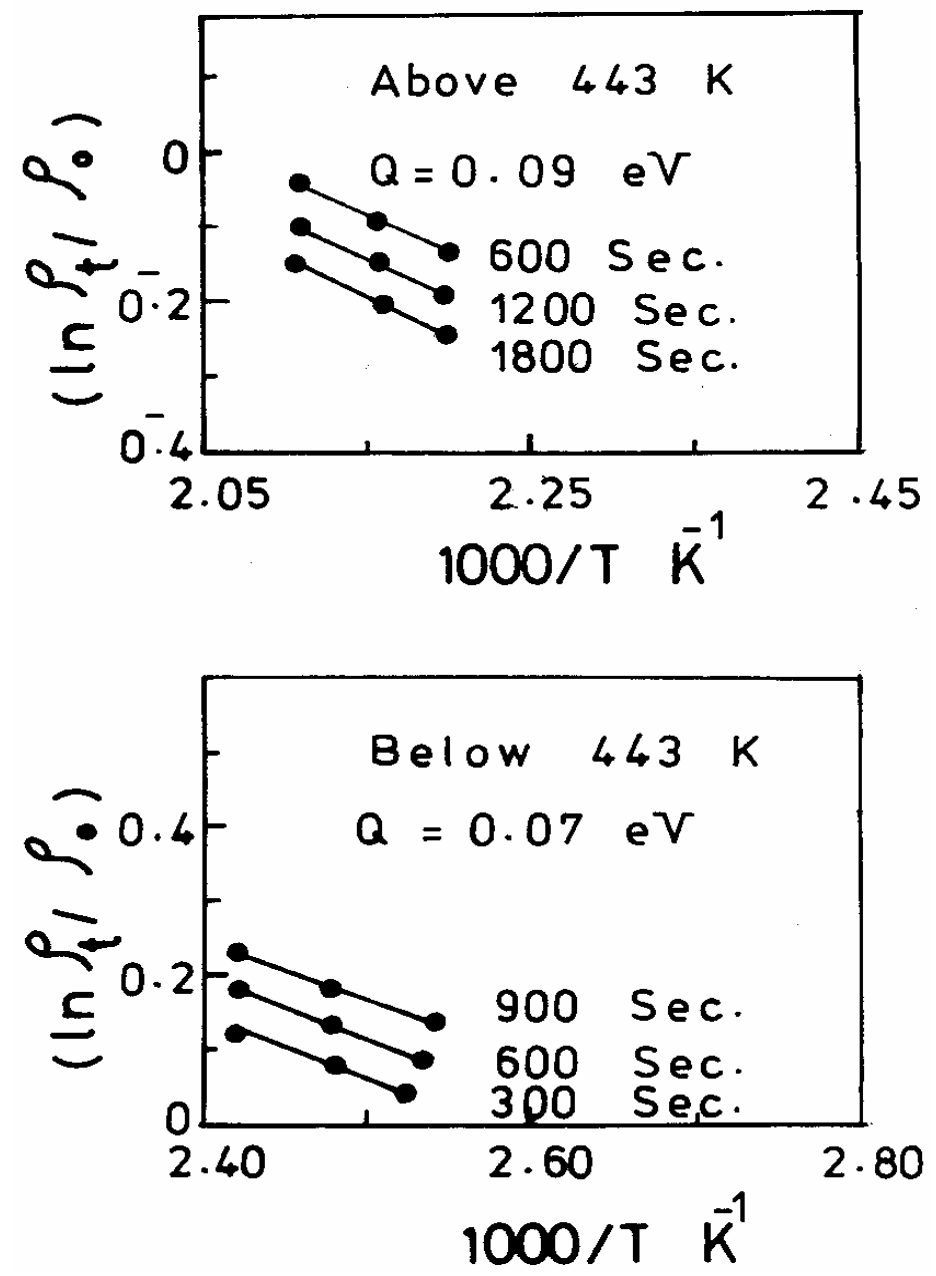

Fig. (13): The relation between in $\ln \left(\rho_{t} / \rho_{0}\right)$ and $10^{3} / \mathrm{TK}^{-1}$ at different ageing times for the annealed $(\mathrm{Pb} / 1.5 \mathrm{wt} \% \mathrm{Sb})$. 
The values of the activation energies between $(0.07-0.12) \mathrm{eV}$ were explained by the binding energy between vacancy and ( $\mathrm{Sb}$ ) solute atom [29].

Figure (14) shows the scanning electron micrograph for the studied alloy at $453 \mathrm{~K}$, showing the segregation of light phase (Sb- rich phase) around the columnar grains of dark phase ( $\mathrm{Pb}$ - rich phase).

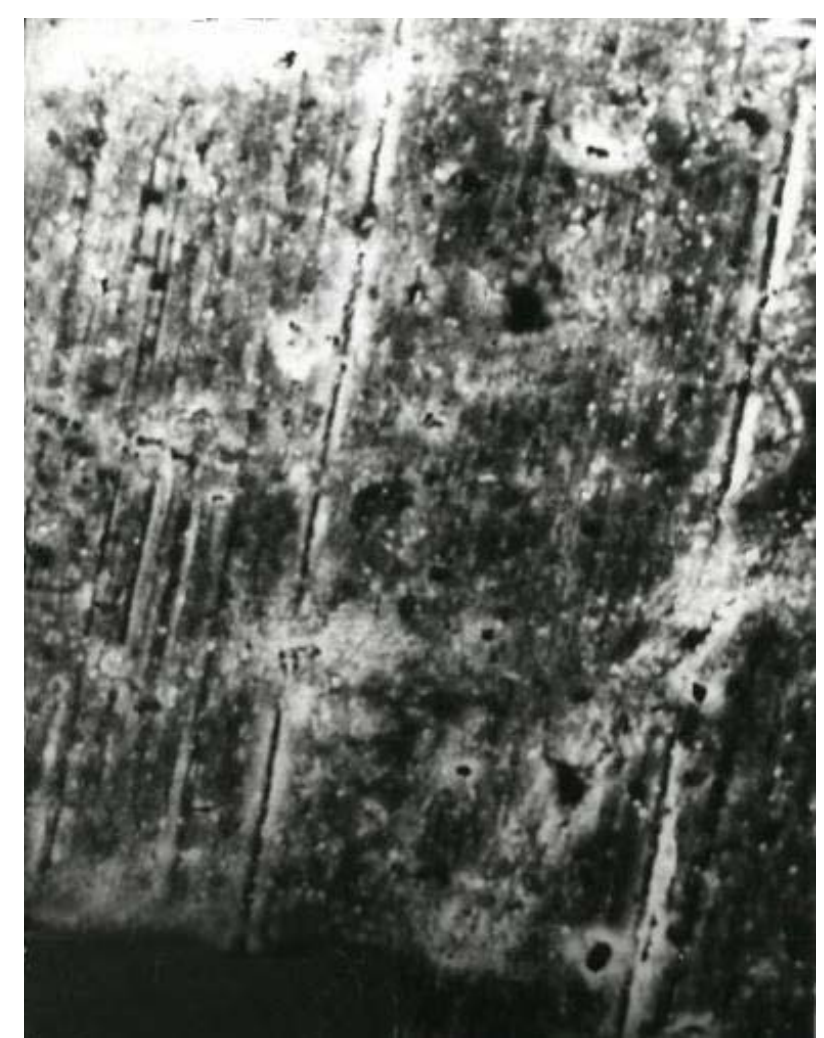

Fig. (14): Scanning electron micrograph for annealed sample of alloy (Pb$1.5 \mathrm{wt} \% \mathrm{Sb}$ ) alloy at $\mathrm{T}=453 \mathrm{~K}$.

The electron micrograph and diffraction pattern for the studied alloy at $443 \mathrm{~K}$ is shown in Fig. (15) showing dark phase ( $\alpha$ - phase) $\mathrm{Pb}$ - rich phase as a columnar grains, and light phase ( $\beta$ - phase) Sb- rich phase.

The microstructure investigation for the studied alloy at $433 \mathrm{~K}$ is shown in Fig (16). From this figure, it is clear that the $\beta$-phase (Sb-rich phase) is segregated around the $\alpha$-phase ( $\mathrm{Pb}$-rich phase), having a column shape, which could be responsible for a high creep, hence the creep rate is increased. 

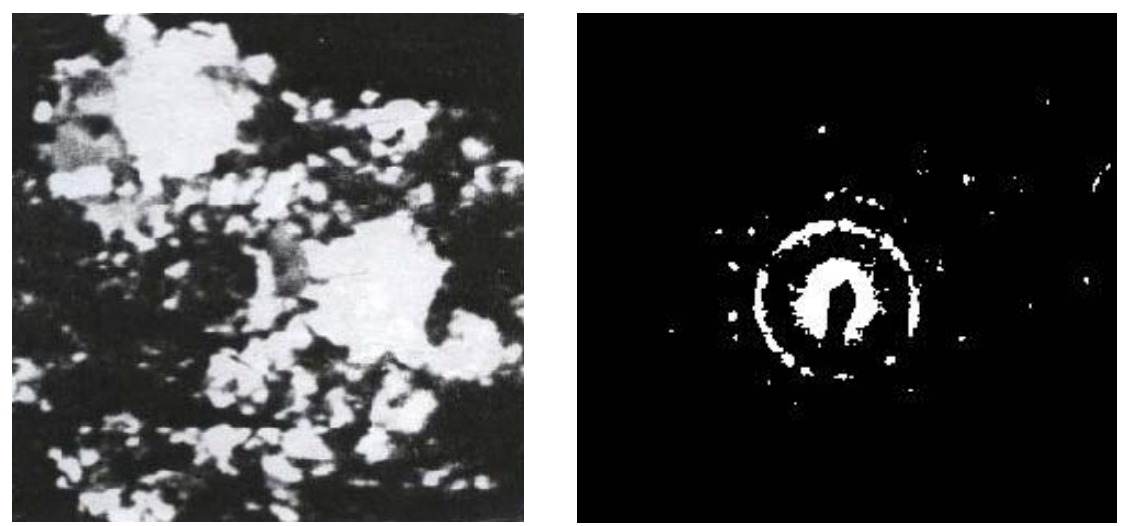

Fig. (15): Electron micrograph and corresponding electron diffraction pattern for annealed sample of alloy $(\mathrm{Pb}-1.5 \mathrm{wt} \% \mathrm{Sb})$ at $443 \mathrm{~K}$.
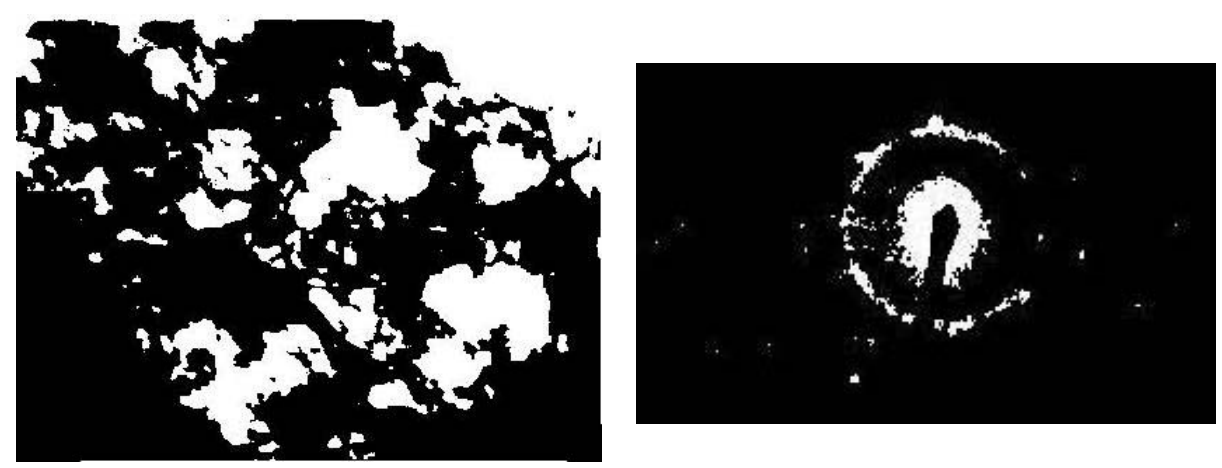

Fig.(16): Electron micrograph and corresponding electron diffraction pattern for annealing sample of alloy $(\mathrm{Pb}-1.5 \mathrm{wt} \% \mathrm{Sb})$ at $433 \mathrm{~K}$.

\section{Conclusion:}

- the obtained results of tensile deformation transient steady creep of the annealed alloy ( $\mathrm{Pb}-1.5 \mathrm{wt} \%$. Sb) showed a transition point at $443 \mathrm{~K}$.

- the strain rate sensitivity parameter $(\mathrm{m})$ at the higher temperature was found to be 0.35 . This was attributed to climb dislocation mechanisms.

- The stress exponent $\mathrm{m}^{\prime}=1 / \mathrm{m}$ for power law creep is $\approx 3$, as expected for power law creep $\left(\sigma^{3}\right)$ of solid solution alloy. Coble creep [30] seem to be the dominant creep mechanism.

- The activation energy of the transient creep for the studied alloy below $443 \mathrm{~K}$ was found to be $52 \mathrm{~kJ} / \mathrm{mole}$ characterizing the grain boundary sliding by dislocation slipping. 
- The activation energy of the steady state creep for the studied alloy above $443 \mathrm{k}$ was found to be $52 \mathrm{~kJ} / \mathrm{mole}$ characterizing the viscous creep.

- X-ray investigation of the crept samples shows that the internal residual strains exhibt a peak value at transient temperature $443 \mathrm{~K}$.

- The activation energy of the formation and dissolution of precipitates in the studied alloy as calculated from the resistivity change were found to be of the order of the binding energy between vacancy and $\mathrm{Sb}$-solute atom.

- The annealing of samples for long time $(2 \mathrm{~h})$ at $503 \mathrm{~K}$, increases the solid solubility associated, produce microstructure with a homogeneous distribution of alloying element $(\mathrm{Sb})$ in the $\mathrm{Pb}$ matrix. This enhanced the creep rate and also increased the hardness of the lead alloys.

\section{References}

1. W.Hofmann, "Lead and Lead Alloys", springer-verlag, New York and Berlin, 341, (1970).

2. J.J. Lander, J.Electrochem. SOC., 99, 339, (1952)

3. J.L. Dowson, M.I. Gilliboand and J. Wilkinson, $1,7^{\text {th }}$ International power sources, symposium, Barrington, England (1970).

4. A. Cameron, "The principles of lubrication", Longman, London, 263, (1966).

5. R. Alarashi, A.M. Shaban and M. Kamal, Mat. letters, 31, 61, (1997).

6. J. Perkins and G.R. Edwards, J. Mat. Sci., 10, 136, (1975).

7. J. Zhiyun, L,Yuandud, Z.Shuzhen, G.Weiging, Z.Zhonghua, J.Power Sources .31,169, (1990).

8. S.N.Komnik, I.T. Ponomarenko, V.I. Startsev, Mat. Sci. Eng. 58, 15, (1983).

9. G.S. Al-Ganainy, M.T. Mostafa, M. R. Nagy, phys.stat. sol., A165, 185, (1998).

10. G.s. Al-Ganainy, M.T. Mostafa, and F.Abd El-Salam, Physica B, 438, (2004).

11. N.V. Isaev, V.S.Fomenko, V.V. Pustovalov, Fiz. Nizk. Temp. 15,759, (1989).

12. A.M. Abd El-Khalek, R.H. Nada, Physica B, 328, 393, (2003).

13. M.M. Mostafa, Physica B, 349, 56, (2004).

14. F. Sitz "The physics of Metals", $\mathbf{1}^{\text {st }}$. Ed, $3^{\text {rd }} . I_{m p}$., Mc Graw-Hill, New York, 312, (1943).

15. A.W. Harisson, Acta Metal, 8, 168, (1960).

16. M.S. Sakr, phys. stat. sol., k37, (a) (126), (1991).

17. M. Amin, G.M. Nasr, S.A. khairy and E.A. Ateia, Die Angeuants Makromeolikulare chemi, 19, (2274), 141, (1986). 
18. B.D. Culity, "Element of X-ray Diffraction" Addison-Wesley Public Company (1958).

19. M. Hansen, "Constitution of Binary Alloys", Mc Graw-Hill publ. co., New York (1958).

20. N.B. Dahotre, M.H. Mc Cay, T.D. Mc Cay and M.M. Kim, J. of Mat. Sci, 27, 6426, (1992).

21. M.S. Sakr, A.A, El-Shazly, M.M Mostafa and H.A. El-Sayed, Czech. J. phys. B38, (1988).

22. P.lukac, A.G. Malygin and V.A. Vladimirova, Czech J. phys., B35, 318, (1985).

23. M.S.Sakr, A.A. El-Daly, E.A.El- Saadani and A.H. Bassyouni, Ain Shams Sci, Bull 28A, 275, (1992).

24. A. Ball and M.M. Hutchison, Metal. Sci. J, 3, 1, (1969).

25. H. Cardes and K. Kim, J.Appl. Phys, 37, 2181, (1966).

26. "Powder Diffaction File" (Inorganic section) 1-40, (JCPDS) International Center for Diffraction Data PA, USA, (1988).

27. M.S Sakr, A.E.E. Abd-El - Raheim and A.A.El-Daly, phys stat sol, (a) 94, 561, (1986).

28. M.M. Mostafa, A.A.El-Shazly, M.S.Sakr and H.A.El- Sayed, Egypt.J.Sol, 2, (15), (1992).

29. J.Szablewski and B.Kuznicha, Mat. Sci. and Tech., (7), 407, (1991).

30. R.C. Cobl, J. appl. Phys., (34), 1979, (1963). 